\title{
J. L. AUSTIN E ALVIN GOLDMAN: CONHECIMENTO EMPÍRICO E ALTERNATIVAS RELEVANTES
}

\section{Luís Fernando Dos Santos Souza'}

\section{RESUMO}

Nosso objetivo neste artigo é discutir o conhecimento empírico a partir das teorias de John L. Austin e Alvin Goldman. Para tal, argumentaremos que a definição tradicional do conhecimento (crença, verdadeira justificada) é insuficiente para tratar de conhecimento empírico. Defenderemos que o modo adequado de analisar o conhecimento empírico deve levar em conta a habilidade do sujeito epistêmico de discriminar a proposição empírica $\mathrm{p}$ de alternativas relevantes para o caso.

Palavras-chave: John L. Austin; Alvin Goldman; Conhecimento empírico; Discriminação; Alternativas Relevantes.

\begin{abstract}
Our aim in this paper is to discuss the empirical knowledge such as John L. Austin and Alvin Goldman's theories. For this, we will argue that the traditional definition of knowledge (justified true belief) is insufficient to deal with empirical knowledge. We will argue that the proper way to analyze the empirical knowledge must take into account the ability of the cognizer to discriminate an empirical proposition $\mathrm{p}$ from relevant alternatives to the case.
\end{abstract}

Keywords: John L. Austin; Alvin Goldman; Empirical knowledge; Discrimination; Relevant alternatives.

\section{Introdução}

Desde o Teeteto de Platão o conhecimento foi tratado como um tipo de opinião correta encadeada (PLATÃO, 1983 \$200-202), o que em termos hodiernos pode ser compreendido como crença verdadeira justificada ${ }^{2}$. Tal definição platônica ficou conhecida como tripartite ou tradicional. A primeira exigência feita por esta definição é que um sujeito epistêmico qualquer $S$, tenha uma crença de conteúdo proposicional. Ou seja, ele deve ter alguma proposição $\mathrm{p}$, como objeto de sua crença para que ele possa vir a saber que $\mathrm{p}$. A segunda condição é a verdade da proposição na qual S crê. Pois, parece

\footnotetext{
${ }^{1}$ Pr. Dr. em Filosofia do Instituto Federal do Piauí.

${ }^{2}$ Confira, por exemplo, em MOSER, P; MULDER, D \& TROUT, J. D. (2004). E DANCY, Jonathan (1985).
} 
bastante razoável que a atribuição de conhecimento exija que a crença seja verdadeira. Um sujeito que creia sempre em falsidade não parece ser alguém a quem atribuiríamos conhecimento, ao contrário atribuir-lhe-íamos ignorância. As duas condições por ora apresentadas, a despeito da sua cogência não parecem ser, em dupla, suficientes para uma análise completa do conceito aqui em tela. Carecemos de um terceiro elemento. Trata-se da justificação epistêmica. É este elemento que fecha a trinca epistemológica aludida na definição tripartite.

A junção da justificação à crença verdadeira parece tornar correta a análise do conceito de conhecimento. A justificação epistêmica pode ser compreendida como o elemento meritório embutido no conceito de conhecimento. Estar justificado em uma crença, via de regra, é ter alguma evidência que conduza à crença de que p é o caso. Alguém que crê em uma proposição verdadeira de modo acidental não parece ser alguém a quem atribuiríamos a alcunha de 'conhecedor'. Crer verdadeiramente por sorte não dá ao agente a estabilidade propiciada pelo conceito de conhecimento. Portanto, a justificação epistêmica (assim como a crença e a verdade) é também um elemento necessário para o conhecimento. Deste modo podemos apresentar formalmente a definição tripartite de conhecimento como segue: $\mathrm{S}$ sabe $\mathrm{p}$ se e somente se $\mathrm{S}$ crê que $\mathrm{p}, \mathrm{S}$ tem justificação para crer que $\mathrm{p}$ e p é verdadeiro.

Essa definição, embora atraente e intuitiva, mostrou sua fragilidade ao ser questionada por Edmund Gettier (1963), que apresentou contraexemplos que conciliavam crença justificada com a verdade acidental. A não acidentalidade da justificação, contudo, não é o único refinamento capaz de resolver os problemas da definição tripartite, já que, algo muito mais simples ainda carece de ajuste, a saber, como tal definição ajudaria na compreensão do que é o conhecimento empírico.

Se analisarmos o argumento de Descartes na primeira das suas Meditações observaremos que a definição tradicional é compatível com o ceticismo acerca do mundo externo. Senão vejamos, para Descartes S sabe que p se e somente se: $S$ crê que p, é verdade que p e $S$ possui justificação infalível de que p. Ou seja, Descartes exige certeza absoluta como condição de 
justificação. A conclusão da primeira meditação cartesiana é um ceticismo radical.

Para que a proposição 'Descartes sabe que está diante da lareira' conte como conhecimento empírico, (afinal Descartes vê a lareira, sente-lha o calor, sente o cheiro da fumaça e ouve o tripitar da lenha em chamas) é exigido da sua teoria, a partir da definição tradicional, a capacidade cognitiva de excluir, eliminar todas as possibilidades de erro. Ou seja, conhecimento empírico requer, dentre outras coisas, que o sujeito saiba que não está sonhando, que não está sendo ludibriado por um gênio maligno ou que não é um cérebro numa cuba sendo manipulado por um cientista maluco. Requer, portanto, que sujeitos cognitivamente limitados ajam epistemicamente como seres onicientes. Deste modo, ao se manter uma visão tradicional do conhecimento e da justificação conclui-se que sujeitos epistêmicos ordinários são alijados da possibilidade mesma de obter conhecimento empírico.

Parece haver algo equivocado nessa história, já que a epistemologia tradicional encontra-se aparentemente abraçada com o ceticismo que conclui pela impossibilidade lógica do conhecimento empírico. Parece totalmente contraintuitivo que nesse momento eu seja logicamente incapaz de saber que estou em minha mesa teclando em meu computador, que João não saiba que está diante de um ipê amarelo ou que Moore não saiba que tem mãos. Para encaminhar uma discussão acerca do conhecimento empírico precisamos reexaminar alguns fundamentos da discussão tradicional e é nesse sentido que examinaremos as influentes teorias de John L. Austin, e Alvin Goldman. Nosso objetivo é mostrar os equívocos da abordagem tradicional e discutir como o conhecimento empírico é possível, dado que possível.

\section{Austin e a Epistemologia}

Austin acentua, de saída, um traço da análise epistemológica que parece ignorada pelas teorias tradicionais, a saber, que o conhecimento empírico é o conhecimento humano atribuído a pessoas cognitivamente limitadas e falíveis. Tais pessoas são propensas ao erro e, por isso mesmo, não são capazes de eliminar todas as dúvidas, ou todas as possibilidades de erro implicadas por um possível caso de conhecimento ordinário ${ }^{3}$. Uma teoria do conhecimento que

\footnotetext{
${ }^{3}$ Como salienta (WILLIAMS, 2012 P. 111) "Praticas avaliativas, incluindo as epistêmicas, são
} 
ignore esse fato estaria, como disse Hume, "lutando sem adversários", uma vez que não estão lançando dúvidas que afetam seres humanos reais em suas práticas epistêmicas comuns.

Outro traço distintivo da teoria de Austin que a separa da tradição é que para ele conhecimento não é apenas um conceito atemporal e estático, antes implica em um tipo de atividade. Conhecimento advém de um tipo de prática que implica a habilidade de discriminar ${ }^{4}$ perceptualmente a proposição/ crença alvo de alternativas contextualmente relevantes para o caso concreto. Segundo Austin os argumentos céticos de tipo cartesiano utilizam termos da linguagem comum de modo distorcido e equivocado. $\mathrm{O}$ modo como isso é feito, entretanto, é sutil e não há um argumento simples que possa refutá-lo. O que temos, segundo ele, é "uma massa de falácias sedutoras (verbais, na maior parte), e é preciso desenredá-las uma a uma” (Austin, 2004 p. 5).

Para ilustrar o ponto tomemos um exemplo oferecido por Barry Stroud sobre os médicos de New York.

Suponha que alguém dá uma notícia sumamente surpreendente sobre a inexistência de um único médico sequer na cidade de Nova Iorque. Parece que isso vai de encontro ao que todos consideramos verdadeiro. Seria realmente assombroso se não houvesse nenhum médico em uma cidade desse tamanho. Quando nós perguntamos como se fez esta extraordinária descoberta, e por quanto tempo durou essa situação, suponha que o portador desta surpreendente notícia diga que ela é verdadeira pois, segundo ele explica, o que ele entende por "médico" é uma pessoa que tem um grau (diploma) de medicina e pode curar qualquer enfermidade concebível em menos de dois minutos. (Stroud, 1984 p. 40).

A manipulação do termo comum 'médico' pode tornar impossível sua aplicação a qualquer caso particular. Se o cético se utiliza dessa manobra será fácil enfrentá-lo, já que, claramente, ele estaria violando nossas práticas ordinárias. Será que o argumento cético consiste em impor uma condição pouco razoável e extravagante, para em seguida concluir que nunca pode ser satisfeita? Segundo Stroud "do mesmo modo que ninguém deixa de ser médico porque deixou muitos pacientes sem cura", assim também "o conhecimento ordinário não será menos conhecimento mesmo quando não cumprimos a

construções humanas, designadas a servir aos propósitos humanos. Portanto, estamos livres para modificá-los diante de problemas inesperados".

${ }^{4}$ Essa ideia foi muito bem explorada em 1976 por Alvin Goldman em um artigo muito influente sobre conhecimento e alternativas relevantes intitulado Discrimination and Perceptual Knowledge. Analisaremos esse texto mais a frente. 
extravagante condição de que devemos saber que não estamos sonhando" (Stroud, 1990 p. 43).

A tese subjacente aqui é a de que o argumento cético não afeta nossas práticas epistêmicas ordinárias e isso se dá, talvez, por que o filósofo não presta atenção suficiente no "tipo de coisa que na realidade acontece quando se pergunta às pessoas comuns: como sabe disso?”. Austin acredita que perguntas do tipo 'como você sabe?' "apenas podem ser feitas por uma curiosidade respeitosa, por motivo de um genuíno desejo de aprender" (Austin, 1980 p. 88). Se as dúvidas céticas são estéreis e extravagantes, elas, simplesmente, erram o alvo. É por esta razão que o argumento, apesar de logicamente rigoroso, não produz qualquer efeito em nossas práticas epistêmicas.

Não é qualquer dúvida, segundo Austin, que é capaz de solapar o conhecimento ordinário ${ }^{5}$. Se o interlocutor, engajado no mesmo contexto conversacional, lança uma dúvida para a qual ele próprio nunca estará satisfeito com as possíveis respostas, então sua dúvida não é razoável, e por consequência é irrelevante para o uso ordinário do conceito. É sempre necessário partirmos de algum lugar. Não se pode atacar a legitimidade dos sentidos por que eles às vezes falham. A confiabilidade dos sentidos, por exemplo, deve ser assegurada "exceto no caso em que haja alguma razão concreta para a desconfiança" (Austin, 1980 p. 91).

O exemplo de Austin é o seguinte. Imagine que você está com um colega no jardim e apontando para uma árvore afirme 'aquele pássaro ali é um pintassilgo'. O seu colega pode lhe perguntar: como você sabe que é um pintassilgo? Você pode responder, simplesmente, que sabe como esses pássaros se comportam; que reconhece a cor da plumagem (e até mesmo o canto desse tipo de pássaro); que a cabeça deles é vermelha e assim por diante. Essa explicação de como você sabe, segundo Austin, é regulado pelo contexto que, por assim dizer, dita as regras do que é que está em jogo quando alguém afirma que sabe. O que se espera é que $\mathrm{S}$ possua a habilidade de discriminar $\mathrm{p}$ de alternativas que se afiguram como relevantes para aquela situação concreta. Essas alternativas contextualmente relevantes formam o contraste contra o

\footnotetext{
${ }^{5}$ Segundo Rasmussen (1984 p. 53) "Doubt must be shown, not just asserted".

${ }^{6}$ Aqui está acentuada a diferença metodológica crucial entre Descartes e Austin. Enquanto Descartes desconfia de tudo até encontrar algo absolutamente certo e indubitável, Austin confia nos sentidos até que haja uma 'razão concreta' em contrário.
} 
qual a afirmação de que $S$ sabe faz sentido. Se mudarmos o contexto arbitrariamente, e por consequência o contraste, a afirmação de conhecimento inicial perde o sentido e a estabilidade. Se você não é capaz de discriminar um pintassilgo de um pica-pau, por exemplo, então você não sabe que é um pintassilgo. Entretanto, naquele contexto as hipóteses do sonho ou cérebro numa cuba estão fora de questão.

Nas dúvidas lançadas há a pressuposição de que o interlocutor tenha uma ideia prévia do que seria suficiente para saber o que é um pintassilgo. O suficiente para saber que é um pintassilgo deve ser compreendido dentro dos limites razoáveis e para os fins e propósitos atuais. Não é suficiente para mostrar que não é um pássaro empalhado, holograma, alucinação ou sonho. Essas possibilidades estão fora do contexto original de atribuição de conhecimento ${ }^{7}$. Se o contexto envolvesse uma loja de equipamentos de alta tecnologia a hipótese do holograma seria relevante. A ideia de que o conhecimento ordinário só faz sentido quando afirmado contra um contraste contextualmente determinado é uma ideia que ocupará grande parte da agenda epistemológica a partir dos anos de $1970^{8}$.

Um detalhe importante sobre a teoria de Austin é que se alguém não está familiarizado com certo objeto e, portanto, não sabe nomeá-lo adequadamente, então esse sujeito não poderá lançar dúvidas razoáveis sobre alguém que alega saber algo sobre esse mesmo objeto. Em uma frase curta numa nota de rodapé Austin enfatiza que "saber o que uma coisa é é, em parte, saber como nomeá-la, e como nomeá-la corretamente" (1980 p. 92). Isso quer dizer que alguém que esteja em outro contexto conversacional não poderá lançar qualquer dúvida razoável. É por isso que Austin rejeita as dúvidas céticas, pois parece claramente que ao utilizar termos como 'conhecimento', e outros termos epistêmicos relacionados, o cético altera as regras do jogo no meio da partida. Suas dúvidas, por não poderem ser satisfeitas, simplesmente não fazem sentido nem alteram nosso uso ordinário dos termos epistêmicos. Desse modo a dúvida cética seria inútil ou irrelevante. Se em uma situação

\footnotetext{
${ }^{7}$ Uma ressalva importante a ser feita aqui é que as hipóteses (ou cenários) céticas são hipóteses lógicas. Há uma grande confusão na literatura quando se tenta dar a tais hipóteses um peso ontológico que elas não possuem. A mera pronúncia de uma hipótese cética não altera a ontologia do contexto atual de atribuição de conhecimento. De outro modo deveríamos encerrar o enfrentamento cético com a clássica disputa metafísica entre realistas e idealistas.

${ }^{8}$ Principalmente a partir dos textos de Dretske (1970;1981); Gail Stine (1976); Alvin Goldman (1976) e David Lewis (1979; 1996).
} 
comum sob boa luz, curta distância e aparato cognitivo funcionando bem, alguém afirma 'isto é uma cadeira', lançar uma dúvida radical sobre esse conhecimento ordinário seria visto pelo homem comum "não como uma dúvida desmedida, excessivamente sofisticada ou pouco prática, mas como um absurdo manifesto" (Austin, 2004 p. 11).

Para Austin, portanto, a exigência cética de que para que $S$ saiba que 'isto é uma cadeira' ele deve saber que não está sonhando ou não é um cérebro numa cuba fere essencialmente nossas práticas epistêmicas mais comuns? Embora Austin não tenha desenvolvido esse ponto vemos claramente que sua estratégia visa negar a validade do princípio de fechamento $^{10}$ sobre o conhecimento ordinário. $\mathrm{O}$ alcance do fechamento seria, desse modo, limitado a algumas possibilidades contextualmente relevantes. Como vimos, a estratégia de Austin não buscou refutar o ceticismo, mas desarmá-lo, como sugeriu Stroud (1990). O que se tentou mostrar foi que ao analisarmos a linguagem que o cético utiliza em seus argumentos observa-se que são falaciosos e infringem a linguagem ordinária, de tal modo que não há ameaça ao conhecimento comum, pois o ceticismo, simplesmente, não faz sentido. Diz Stroud que para Austin a distorção real e a irracionalidade residem precisamente na insistência desta condição geral tão estrita para o conhecimento. Em situações ordinárias a alternativa cética é ridícula e irrelevante. Ela não afeta o conhecimento ordinário.

\section{Discutindo a teoria de Austin}

A teoria de Austin não tem como objetivo refutar o ceticismo. $\mathrm{O}$ argumento cético permanece intacto logicamente, mas uma das suas premissas foi colocada em suspeição. A premissa que faz uso do princípio de fechamento,

\footnotetext{
${ }^{9}$ Oportunamente Oswaldo Porchat nos lembra que "o estranho e curioso paradoxo do ceticismo está em que ele instala decididamente a filosofia no seio da vida comum. Se me permitem a expressão, ele a infesta de filosofia, para fazer a filosofia triunfar sobre ela e reduzila." E conclui dizendo que "tentando convencer-nos de que os homens comuns fazem filosofia sem saber, o ceticismo rejeita toda pretensão humana ao saber, ao conhecimento, à verdade." (Porchat, 2007 P. 87)

${ }^{10}$ O princípio de fechamento é um princípio de lógica epistêmica que afirma, em uma das suas versões mais básicas, que se $\mathrm{S}$ sabe que $\mathrm{p}$, e $\mathrm{S}$ sabe que p implica q, então $\mathrm{S}$ sabe que q. $\mathrm{O}$ princípio visa assegurar a expansão do conhecimento através da dedução. Esse princípio, como bem observado por Moore, é uma faca de dois gumes já que pode servir tanto ao epistemista quanto para o cético. Descartes, como vimos no início do texto, utiliza-se de uma versão desse princípio para extrair uma conclusão cética.
} 
ou a condição de Descartes como nomeou Barry Stroud, é a chave da disputa. Sem a aceitação do fechamento, ou seja, "Sem a condição de Descartes para o conhecimento, o ceticismo filosófico estará completamente desarmado" (Stroud, 1990 p. 49).

A insistência de Austin nesse ponto tem um apelo intuitivo muito forte. Imaginemos um tribunal em que o réu está prestes a ser condenado por assassinato. Uma testemunha ocular diz em juízo que viu o réu cometer o crime a poucos metros de onde ela estava; que conhecia o histórico de violência entre o réu e a vítima e que, inclusive, gravou o homicídio. O advogado de defesa como último recurso (a cartada final) lha inquire com altivez 'como você sabe que não é um cérebro numa cuba tendo apenas a ilusão de ter visto um assassinato?'. Como levar a sério tal questionamento? Certamente parecerá a todos que o desespero pela derrota iminente fez com que o advogado perdesse a razão.

Realmente as hipóteses céticas, dada a sua extravagância, podem ser ignoradas até mesmo em um ambiente de alto padrão como um tribunal. Mesmo em um contexto tão exigente elas ainda parecem inadequadas. Se não há qualquer razão especial para se conceber a hipótese de que a testemunha possa ser um cérebro numa cuba, então “esta suposta possibilidade não está em discussão, de tal sorte que a possibilidade aludida por ela [...] não seria nenhum obstáculo para o conhecimento [...] nesses casos” (Stroud, 1990 p. 53).

Embora a teoria de Austin seja promissora e intuitiva há alguns problemas com ela. Faltou uma explicação adicional sobre o que torna a hipótese cética absurda ou inconveniente. A irrelevância da hipótese cética para fins práticos não implica que ela é falsa. Temos que separar a discussão sobre o que é adequado, razoável, garantido ou justificado daquilo que é verdadeiro ou falso. É aceitável conceder, como o faz Stroud (1990 p. 55) que "normalmente, as condições para a alegação racional/razoável coincidem com as condições de verdade". Mas isso está longe de ser óbvio ou decisivo. Uma proposição altamente improvável e absurda pode se revelar verdadeira, ao passo que uma afirmação razoável e justificada pode se revelar falsa.

Como dissemos acima, nem toda possibilidade extravagante ou improvável é falsa. Imaginemos que Ralf faltou à aula de filosofia e o professor perguntou a João, um dos amigos do Ralf, se ele sabia o motivo da ausência. 
Para dar uma resposta descontraída João afirmou que Ralf havia ganhado um grande prêmio na loteria e se mudara do país. De tão improvável, a hipótese inventada na hora pelo João foi ignorada sem que qualquer um soubesse que o Ralf, de fato, havia ganhado na loteria e se mudado do país. A hipótese de Ralf ter ganhado o prêmio da loteria não seria tão improvável ou absurda quanto a hipótese do sonho ou do cérebro numa cuba? No final das contas essas hipóteses podem, mesmo que remotamente, serem verdadeiras. A nosso ver é justamente aí que reside a força do argumento cético, na impossibilidade de mostrar que ele é falso.

Desse modo cremos que Austin estava a discutir as condições de justificação (assertabilidade garantida) ou crença apropriada, não conhecimento (que implica verdade). Outra crítica endereçada ao tratamento que Austin deu ao ceticismo é que não se fez uma separação clara entre a dimensão prática e teórica do conhecimento. Ou seja, entre o que é apropriado e necessário para a ação e o que é apropriado e necessário para o conhecimento (e a verdade). A sugestão de Stroud é a de que os adeptos da "vida comum" estão mais interessados em argumentar pela racionalidade das práticas comuns. A prática é regulada por vários fatores e talvez a verdade não seja o mais importante. As circunstâncias mudam e é difícil estabelecer um critério geral para a ação.

O desafio cético, tal como expusemos anteriormente impõe a condição de que sejam eliminadas/excluídas todas as possibilidades 'lógicas' para que "S saiba que p" e não todas as possibilidades práticas, ou razoáveis de situações específicas. Do fato de que podemos ignorar as hipóteses céticas em nossas práticas epistêmicas ordinárias não se segue que elas não precisem ser eliminadas para o conhecimento do mundo externo.

É crucial para Austin a constatação de que o cético manipula o sentido comum de termos epistêmicos. Essa tese, com efeito, é problemática. É fundamental para a solidez do argumento que o significado dos termos em disputa permaneça inalterado ${ }^{11}$. Se o termo conhecimento possui um significado na vida comum e outro significado na filosofia, então não há disputa legítima, mas um grande equívoco de ambas as partes. Segundo Peter Unger (1975) o cético compartilha conosco a mesma concepção de

${ }^{11}$ A tese de que os termos epistêmicos não variam de significado de um contexto para o outro foi batizada como Invariantismo em oposição ao contextualismo. Um dos primeiros a defender explicitamente a tese de que 'conhecimento' possui dois sentidos, um fraco e um forte, foi o discípulo de Wittgenstein Norman Malcolm em seu Knowledge and Belief de 1952. 
conhecimento, todavia, nós a relaxamos apenas para fins práticos (pragmáticos). Segundo Stroud (1990 p. 65) "há apenas uma concepção de conhecimento [...] porém, esta concepção opera na vida cotidiana sob os imperativos da prática social e as exigências da ação, da cooperação e da comunicação".

Quando se diz que, para efeitos práticos, 'S sabe' o que se quer dizer, provavelmente, é que ele está fazendo tudo o que é apropriado para aquele contexto, apesar de o que ele diz, analiticamente falando, possa ser considerado não como conhecimento, mas ignorância justificada. Essa abordagem linguística do problema do mundo externo nos da uma visão alternativa, mas parece-nos limitada e ineficaz contra o ceticismo.

\section{Goldman e as Alternativas Relevantes}

Nesta seção apresentaremos a teoria do filósofo Alvin Goldman vinculando alguns elementos de sua abordagem epistemológica com a teoria das alternativas relevantes. Goldman é um autor de vasta literatura epistemológica, por esta razão cabe frisar que apenas o texto Discrimination and Perceptual Knowledge de 1976 nos ocupará aqui ${ }^{12}$. Nesse texto Goldman propõe uma análise relevantista do conhecimento empírico adicionando um importante elemento à mesma, a saber, a confiabilidade dos procedimentos envolvidos na formação e sustentação da crença. Para este filósofo a eliminação de uma alternativa não terá qualquer relação com a 'qualidade' ou 'posse' de evidência por parte de S, como defendem as teorias internalistas da justificação. Para ele eliminar uma alternativa q contrária à p é algo que deve ser compreendido observando a capacidade do aparato cognitivo de S de discriminar ou diferenciar empiricamente um estado de coisas em que p ocorre de outro em que q seria o caso. Por dispensar o sujeito do conhecimento de

\footnotetext{
12 Aspectos cruciais da teoria apresentada neste ensaio foi revista e reformulada em escritos posteriores. O aspecto normativo da justificação já foi reconhecido em 1979 e mais bem trabalhado em 1986. Esses textos são cruciais para um melhor entendimento do projeto epistêmico geral proposto por Goldman, todavia, não nos ocuparemos deles aqui. Um elemento que parece intocável em todos os escritos é a recusa da epistemologia tradicional (cartesiana) e todas as suas implicações. Goldman havia esboçado importantes elementos de sua filosofia em artigos anteriores ao de 1976, destacaremos aqui seu texto de 1967, em que fornece uma teoria causal do conhecimento. Neste último, que terá ecos no texto de 1976, Goldman parece convicto que a solução de grande parte dos problemas da epistemologia poderiam ser ensejados pelos resultados teóricos da Epistemologia Naturalizada, proposta de modo explícito por Quine.
} 
acesso reflexivo ao seu conteúdo mental Goldman nos oferecerá uma teoria externalista do conhecimento empírico.

Goldman é frequentemente citado como um dos primeiros epistemólogos a adotar alguma versão das alternativas relevantes. Sua ênfase na confiabilidade dos mecanismos cognitivos que geram crenças de conteúdo epistêmico visa corrigir sua velha teoria causal apresentada em 1967. Suas antigas suspeitas, apresentadas em 1967, o levou a estabelecer como um requerimento para o uso correto do conceito de conhecimento a conexão causal entre a crença de $\mathrm{S}$ de que $\mathrm{p}$ com o fato, ou estado de coisas, de que $\mathrm{p}^{* 13}$. Este requerimento é abandonado, posto que a adequada relação causal não impede o sujeito $\mathrm{S}$ de atingir a verdade da crença $\mathrm{p}$ apenas acidentalmente ${ }^{14}$. Tendo isso em mente, Goldman refina sua teoria causal exigindo agora que os processos ou mecanismos envolvidos na formação (e sustentação) da crença sejam 'confiáveis'. Para Goldman, de um modo geral, podemos entender a confiabilidade da seguinte maneira: "um mecanismo ou processo cognitivo é confiável se produz crença verdadeira não apenas na situação atual, mas produziria crença verdadeira, ou no mínimo inibiria crença falsa, em situações contrafactuais relevantes" (Goldman 1976. p. 270). O uso de contrafactuais será uma das principais características da teoria do conhecimento ensaiada por Goldman em 1976. A relevância será indexada aos contrafactuais.

A análise proposta para o conceito de conhecimento empírico depende de uma característica intrínseca a este conceito que foi, segundo Goldman, preterida ou simplesmente negligenciada pelos filósofos tradicionais. Trata-se de entender o 'conhecimento' como a capacidade de $\mathrm{S}$ distinguir ou discriminar estados de coisas distintos p e q. Alguém que sabe que p, 'há uma laranja diante de mim', é capaz de discriminar este estado de coisas de, por exemplo, q, 'há uma maçã diante de mim'. O estado de coisas descritos em q geraria uma crença diferente em S. Ao alegar que p, S está operando de modo discriminatório (mesmo que isso lhe seja alheio). Perceber que p é concomitantemente discriminar $\mathrm{p}$ de estados de coisas relevantes contrários à verdade de que p. Neste sentido a primeira apresentação do conceito de conhecimento empírico oferecida por Goldman é a seguinte: [de] “Uma pessoa

\footnotetext{
13 'p*' representa o fato ou estado de coisas declarado pela proposição 'p'.

14 O problema da acidentalidade da crença verdadeira foi apresentado em 1963 por Edmund Gettier, em seu decisivo artigo Is Justified True Belief Knowledge?.
} 
é dita saber que $\mathrm{P}$ apenas no caso em que ela 'distingue' ou 'discrimina' a verdade de $\mathrm{P}$ de alternativas relevantes" (Goldman, 1976 P. 270). O apelo à relevância visa contemplar nossas intuições ordinárias acerca do conhecimento, pois nestes casos alegações epistêmicas não parecem demandar a eliminação (discriminação) de 'todas' as alternativas contrárias à verdade de que $\mathrm{P}^{15}$. Para tornar mais intuitiva as pretensões de Goldman analisemos um caso proposto por ele, segue:

Henry está dirigindo pelo campo (countryside) com seu filho. Para informar o seu filho Henry identifica vários objetos na paisagem tais como ele os vê. "Isto é uma vaca", diz Henry, "Isto é um trator", "Isto é um silo", "Isto é um celeiro" etc. Henry não tem dúvida sobre a identificação daqueles objetos; em particular ele não tem dúvida de que o último objeto mencionado é um celeiro, que na realidade o é. Cada um dos objetos identificados tem características deste tipo. Além disso, cada objeto está completamente em sua vista, Henry possui uma excelente visão e ele teve tempo suficiente para raciocinar cuidadosamente, uma vez que havia um tráfego muito pequeno para distraí-lo. (Goldman, 1976 P. 270).

De posse apenas das informações oferecidas pelo caso diríamos que Henry sabe que está diante de um celeiro? Parece fortemente intuitivo atribuir conhecimento à crença de Henry sobre a existência de um celeiro em seu campo visual. Goldman nos pede que contrastemos essa nossa inclinação inicial em atribuir conhecimento perceptual a Henry com a inclinação que teríamos se algumas informações adicionais fossem adicionadas ao caso. Suponhamos os seguintes fatos:

Embora Henry desconheça, o distrito [em que ele dirige] está repleto de cópias falsas de celeiros feitos de Papel-machê. Da estrada aquelas cópias parecem exatamente com os celeiros [reais], mas são apenas fachadas, sem paredes internas ou por detrás, completamente incapazes de serem utilizadas como celeiro. Eles são tão engenhosamente construídos que os viajantes os confundem invariavelmente com celeiros. (Goldman, 1976 P. 270).

Apesar dos falsos celeiros presentes no distrito em que Henry entrou, ele não viu qualquer um desses, o celeiro que ele viu é um celeiro legítimo. Ainda assim, continuaríamos a atribuir conhecimento empírico à crença de Henry de que o que ele vê é um celeiro? Lembremos que o que ele vê é um

\footnotetext{
${ }^{15}$ Neste sentido Goldman é enfático ao afirmar que “o qualificador 'relevante' desempenha um importante papel em minha teoria. Se conhecimento requisesse a eliminação de todas as alternativas logicamente possíveis, não haveria conhecimento (pelo menos de verdades contingentes). Se somente alternativas relevantes necessitam ser excluídas, entretanto, o escopo do conhecimento seria substancial”. (Goldman 1976, p. 271-272).
} 
celeiro, de fato. Parece que a presença de falsos celeiros nas imediações faz com que extraiamos a atribuição de conhecimento alegada na primeira versão do caso. A questão central a ser discutida é por que há tal oscilação atributiva. Para Goldman tanto sua velha teoria causal quanto as teorias tradicionais do conhecimento, aquelas que o tratam como um tipo de crença verdadeira justificada, não seriam capazes de explicar por que nossas intuições atributivas variam de um caso para o outro. Nos dois casos apresentados S dispõe da mesma crença verdadeira justificada de que 'há um celeiro diante de si'. As abordagens tradicionais teriam que atribuir ou negar conhecimento em ambos os casos. Já a teoria causal que Goldman ensaiou em 67 seria insuficiente para tratar o caso, posto que a crença de $\mathrm{S}$ está conectada causalmente com o fato que gera a crença de $\mathrm{S}$ de que $\mathrm{p}$, a saber, a presença do celeiro [real] em seu campo visual.

Como então a teoria discriminatória de Goldman poderia tratar o caso do celeiro citado acima? A sugestão é a seguinte. Se para que $S$ saiba que p o estado atual de coisas em que p é verdadeiro deve ser distinguivel ou discriminável para $\mathrm{S}$ de um possível estado de coisas relevantes em que p seria falso, então, a oscilação atributiva pode ser explicada da seguinte maneira. No primeiro caso atribuímos conhecimento empírico à crença de Henry acerca do celeiro porque não há qualquer estado de coisas relevantes possível em que Henry creria falsamente que p. Se há, contudo, uma alternativa relevante que S não é capaz de discriminar, então a crença dele não contaria como conhecimento. $\mathrm{Na}$ segunda parte do caso, entretanto, há a inserção de uma alternativa relevante à verdade de que p que o aparato cognitivo responsável pela formação da crença de Henry de que p não consegue discriminar. Se Henry estivesse diante de um falso celeiro ele creria falsamente estar diante de um celeiro real. Neste caso a presença de fachadas de celeiros nas vizinhanças do distrito em que Henry adentrou desqualificaria sua crença de que p. Assim, diante dessas novas alternativas Henry não sabe que $\mathrm{p}^{16}$.

\footnotetext{
${ }^{16}$ Cabe lembrar que a mera possibilidade lógica da presença dos falsos celeiros não é capaz de tornar tal possibilidade relevante. Suponhamos que não haja falsos celeiros no distrito em que Henry entrou, mas apenas na Suécia, ou ainda que apenas um desses facsimilis tenha existido na Suécia, mas que já não existe mais. Essas possibilidades contariam como relevantes? Para Goldman claramente não, posto que estas alternativas poderiam ser desqualificadas contrafactualmente. Cf. (p. 271-272).
} 


\section{O que conta como uma Alternativa Relevante para Goldman?}

O principal desafio a ser vencido pelos relevantistas é o estabelecimento de critérios adequados que possibilitem identificar corretamente alternativas como relevantes ou irrelevantes. Dizer simplesmente que algumas possibilidades, como as apresentadas pelos céticos, são irrelevantes apenas por serem exóticas ou extravagantes parece um tanto ad hoc.

O primeiro requisito para que uma alternativa se torne relevante é que ela seja 'empiricamente equivalente' à crença de S de que p. Para Goldman, "uma alternativa que desqualifique uma crença perceptual verdadeira de ser conhecimento perceptual deve ser uma "percepção equivalente" do atual estado de coisas" (Goldman, 1976 P. 274). O novo conceito inserido por Goldman de 'percepção equivalente' não parece tão claro. Mas o filósofo o define da seguinte maneira: "um equivalente perceptual de um estado de coisas é um estado de coisas possível que produziria a mesma, ou suficientemente similar, experiência perceptual” (Idem). A exigência de uma percepção equivalente para que uma alternativa se torne relevante visa dar conta de certos casos em que a atribuição de conhecimento empírico é negada por causa da mudança do 'método' empregado por S em t para adquirir sua crença de que $\mathrm{p}$. Vamos ver como isso se dá através do seguinte exemplo. Suponha que Oscar está de pé em um campo aberto, em que está Dack o dachshund ${ }^{17}$. Oscar vê Dack e forma (não inferencialmente) a crença em p 'O objeto ali é um cão'. Agora suponha que q 'O objeto ali é um lobo' seja uma alternativa relevante (uma vez que lobos são frequentes nesses campos). Suponha adicionalmente que Oscar tem uma tendência de confundir lobos com cães (ele os confunde com malamutes e pastores alemães). Tomando apenas a proposição p e sua alternativa relevante $\mathrm{q}$ poderíamos dizer que Oscar não sabe que p por causa da ocorrência de lobos no local? Para Goldman seria errado negar que Oscar sabe que p por que o método (a percepção) que gerou a crença de que p, isto é, a visão do cão da raça duchshund é suficientemente diferente do método (a percepção) que geraria a crença de que q. Embora Oscar confunda lobos com cães (malamutes e pastores) a crença de que $\mathrm{p}$ foi gerada pela presença de um cão que nada tem a ver com um lobo. Ou seja, embora a presença de um não-

\footnotetext{
${ }^{17}$ Dachshund é uma raça de cães que se caracterizam por suas pernas curtas e corpo alongado. No Brasil esses cães se tornaram populares graças a uma série de propagandas de amortecedores (Cofap).
} 
cão pudesse gerar a crença $\mathrm{p}$ em Oscar esta crença não seria formada pelo mesmo 'método' que ele utilizou para produzir sua crença de que p. Elas não seriam perceptos equivalentes. Negar que Oscar saiba que Dack é um cão por que ele se confunde certos cães com lobos seria um erro ${ }^{18}$.

\section{Equivalência perceptual}

O conceito de equivalência perceptual é bastante importante para determinar quais alternativas são relevantes em uma alegação de conhecimento empírico, por esta razão nos deteremos um pouco mais sobre este conceito. Os critérios adotados por Goldman para a definição deste conceito devem ser relativizados. Tal relativização deve levar em conta que pessoas diferentes possuem percepções diferentes do mesmo objeto de acordo com o modo como o objeto se lhe apresenta, como ela está direcionada (espacialmente) frente ao objeto e por certas condições ambientais (boa luz, ausência de obstáculos entre o observador e o objeto, dentre outros). Assim, uma definição mais precisa de equivalência perceptual deve ser especificada a partir de pelo menos três aspectos: (1) um objeto, (2) um conjunto máximo de propriedades não-relacionais (propriedades que fazem com que um x seja em x) e (3) uma relação $\mathrm{DOE}^{19}$. Se $\mathrm{S}$ percebe $u$ m objeto $\mathrm{b}$ em $\mathrm{t}$ e se $\mathrm{b}$ tem todas $\mathrm{as}$ propriedades num conjunto máximo $\mathrm{J}^{20}$ e suporta a relação DOE $\mathrm{R}$ para $\mathrm{S}$ em t, então o estado de coisas atuais pertencentes a este episódio perceptual é representado pelo ordenamento triplo (b, J, R). Dado esse conjunto de fatores envolvidos em uma percepção, quando uma alternativa (c,K,R*) é um equivalente perceptual de $(\mathrm{b}, \mathrm{J}, \mathrm{R})$ para $\mathrm{S}$ em $t$ ? A resposta oferecida pelo filósofo é a de que uma situação alternativa é um equivalente perceptual para $S$ na situação atual, se o percepto produzido pelo estado de coisas não diferiria do percepto atual em qualquer aspecto que seja causalmente relevante para a crença de S. Para fechar a definição de equivalente perceptual Goldman acrescenta uma última relativização, uma vez que uma identificação perceptual

\footnotetext{
${ }^{18}$ Esta tese embrionária aqui será amplamente desenvolvida por Jonathan Schaffer (2004; 2005) a partir do Contrastivismo Epistêmico.

${ }^{19}$ Relação DOE (distance-orientation-enviroment) resume as condições ideais de observação de um objeto, tais como distancia adequada, orientação espacial privilegiada e boas condições ambientais.

${ }^{20} \mathrm{~J}$ está representando o conjunto máximo de todas as propriedades que fazem com que um objeto b seja percebido como um b.
} 
é sempre relativa a certa propriedade do objeto percebido, Goldman a chamará de propriedade F. No caso da situação-lobo, presente no exemplo supracitado, o que está em jogo para a percepção de Oscar é a propriedade de Dack ser um cão ${ }^{21}$. Uma vez definido todas as características que uma percepção deve ter para que seja contada como uma alternativa relevante para $\mathrm{p}$ de $\mathrm{S}$ em t, apresentaremos como este elemento engendra a definição de conhecimento empírico formulada por Goldman.

\section{Definição de conhecimento empírico}

Em $t$, S sabe perceptualmente e de modo não inferencial do objeto $b$ que tem a propriedade $F$ se e somente se:

(1) Para algum conjunto máximo de propriedades não relacionais $\mathrm{J}$ e alguma relação DOE $\mathrm{R}$, o objeto b tem (todos os membros de) J em t e está em $\mathrm{R}$ para $\mathrm{S}$ em $\mathrm{t}$,

(2) F pertence a J,

(3) (A) b tendo $\mathrm{J}$ e estando em $\mathrm{R}$ para $\mathrm{S}$ em $\mathrm{t}$ causa perceptualmente em $\mathrm{S}$ em $\mathrm{t}$ algum percepto $\mathrm{P}$,

(B) P causa não inferencialmente em $\mathrm{S}$ em t a crença (ou sustenta a crença de S) no objeto b que possui a propriedade $\mathrm{F}$, e

(C) Não há um estado alternativo de coisas $\left(c, K, R^{*}\right)$ tal que,

(i) $\left(c, K, R^{*}\right)$ é um equivalente perceptual relevante de $(b, J, R)$ para $\mathrm{S}$ em $\mathrm{t}$ relativo à propriedade $\mathrm{F}$, e

(ii) F não pertence a K. (Goldman, 1976 P. 277).

Ao definir conhecimento empírico nesses termos Goldman torna explícita a importância desempenhada pelas alternativas relevantes em sua definição. Isso pode ser identificado no item (3C). Esta cláusula nos diz em que condições deve estar nossa crença para que ela conte como conhecimento. Um

\footnotetext{
${ }^{21}$ A definição completa de uma percepção equivalente é dada desta maneira: Se o objeto $b$ tem o conjunto máximo de propriedades $J$ e está na relação DOE R para $\mathrm{S}$ em $t$, se $\mathrm{S}$ tem algum percepto $\mathrm{P}$ em $t$ que é causado perceptualmente por $b$ tendo $J$ e estando em $R$ para $S$ em $t$, e se $P$ causa não inferencialmente a crença de $S$ (ou sustenta a crença de $S$ ) no objeto $b$ que tem a propriedade $F$, então $\left(\mathrm{c}, \mathrm{K}, \mathrm{R}^{*}\right)$ é um equivalente perceptual de $(\mathrm{b}, \mathrm{J}, \mathrm{R})$ para $S$ em t relativo a propriedade $F$ se e somente se:Se em $t$ o objeto $c$ tivesse $\mathrm{K}$ e estivesse em $\mathrm{R}^{*}$ para $\mathrm{S}$, então isto causaria perceptualmente em $S$ algum percepto $P^{*} \mathrm{em} t . P^{*}$ causaria não inferencialmente a crença em $S$ (ou sustentaria a crença de $S$ ) no objeto $c$ que tem $F$, e $P^{*}$ não diferiria de $P$ em qualquer aspecto que fosse causalmente relevante para a crença [causada pela propriedade] $F$ de $S$. (Goldman, 1976. P.276).
} 
estado de coisas alternativo relevante que não pode ser discriminado perceptualmente por $\mathrm{S}$, como já nos é patente a essa altura, faz com que sua crença não figure como conhecimento.

Em resumo o que Goldman diz de sua análise do conhecimento é que "S tem conhecimento empírico se e somente se seu mecanismo perceptual não apenas produz crença verdadeira, mas não haveria situação contrafactual relevante em que a mesma crença seria produzida via uma percepção equivalente e na qual a crença seria falsa" (Goldman, 1976 P. 278). Claramente, na segunda parte do caso do celeiro, apresentado acima, temos uma inadequação com o critério estabelecido aqui. Lá é inserido um contrafactual relevante que o aparato cognitivo de Henry não seria capaz de confiavelmente discriminar (excluir). Se houvesse simulacros de celeiros em seu 'campo visual' a mesma crença seria formada, embora falsa (no caso original há celeiros falsos na vizinhança, de fato, mas eles não estão no campo visual de Henry. Digo isso para que não seja atribuído erroneamente a Goldman um subjuntivo apenas hipotético). A não atribuição de conhecimento se deveu ao fato da crença de Henry ter violado a cláusula $3 \mathrm{C}$ da definição de conhecimento empírico. Justamente a cláusula que insere as alternativas relevantes.

A inserção das alternativas relevantes serviu-lhe, nos parece, para tornar explícito certas características do conceito de conhecimento empírico em seu uso ordinário. A abordagem epistemológica de Goldman é importante não apenas pelas razões apresentadas a partir do ensaio do qual nos ocupamos aqui, mas por que lança uma importante e sólida frente diante da epistemologia tradicional, à qual denominou teorias 'cartesianas'. Seu caráter inovador, ao dispensar o sujeito do conhecimento da necessidade de acesso reflexivo ao que justifica a crença de S de que $\mathrm{p}$ (requerimento central da filosofia internalista), preparou o terreno para as teorias externalistas, não apenas do conhecimento (o que seria um truísmo), mas da justificação doxástica, dentre as quais seu confiabilismo figura como uma das mais importantes.

\section{Considerações Finais}

Tanto Austin quanto Goldman apresentam visões alternativas à abordagem tradicional. Ambos apelam para algo essencial ao conhecimento empírico que é a habilidade que o sujeito epistêmico tem que possuir de 
discriminar $\mathrm{p}$ de alternativas relevantes para o caso. Essa abordagem evita as excessivas exigências demandadas pela definição tradicional que, como vimos no início do texto, é compatível com o argumento cético cartesiano.

Austin foi muito importante para essa reformulação pela qual a epistemologia contemporânea passou, apesar de não receber os créditos devidos. Sua teoria lançou as bases da teoria do conhecimento dos anos 1970 em diante. Em primeiro lugar por que corrigiu os excessos dos argumentos céticos que abusavam da linguagem ordinária, e em segundo lugar por que não buscou refutar o ceticismo, mas desarmá-lo. Buscou mostrar suas falhas e sua irrelevância. Embora suas ideias tenham sido inspiradoras e úteis para o enfrentamento do ceticismo e para o correto entendimento do conhecimento empírico o próprio Austin não levou suas teses às últimas consequências.

A despeito das virtudes enumeradas aqui a teoria de Austin ficou exposta a uma crítica que reputo da mais alta importância. A acusação é de que a abordagem pragmática de Austin o impede de acomodar a questão da verdade ao conhecimento. No limite o que a teoria de Austin nos permite concluir quais são as proposições legítimas, significativas e razoavelmente atribuídas em contextos ordinários, mas é silente, sobre se proposições ilegítimas ou absurdas são, em virtude disso, falsas.

A teoria de Goldman, por sua vez, consegue acomodar a verdade, mas rejeita a exigência cartesiana de uma justificação infalível. Se a exigência tradicional estivesse correta apenas seres omniscientes teriam conhecimento. Contudo, no que toca o enfrentamento das hipóteses céticas a teoria de Goldman é ultramodesta. Segundo ele sua teoria do conhecimento empírico não seria capaz de fornecer elementos suficientes para derrotá-las. Em virtude disso ele afirma que sua "análise oficial, portanto, é neutra sobre a questão do ceticismo" (Goldman, 1976 p. 273). Embora uma análise correta do conceito de conhecimento implique na refutação do ceticismo (local ou global) Goldman não se deteve nesta árdua tarefa neste ensaio. O que ele faz é apontar para o caminho que levará a isso.

\section{Referências bibliográficas}

AUSTIN, J. L. Outras Mentes. In Coleção os pensadores. São Paulo-SP, Abril Cultural, 1980. 
. Sentido e Percepşão. São Paulo-SP, Ed. Martins Fontes, 2004.

DANCY, Jonathan. Epistemologia Contemporânea. Lisboa: Edições 70, 1985.

DESCARTES, René. Meditações. São Paulo: Abril Cultural, 1973.

GAIL, Stine. Skepticism, Relevant Alternatives, and Closure. In: Philosophical Studies 29: p. 249 - 261. 1976. Reimpresso em: Keith DeRose and Ted A. Warfield eds., Skepticism: A Contemporary Reader. New York Oxford: Oxford University Press: p. $145-155.1999$.

GOLDMAN, Alvin. Discrimination and Perceptual Knowledge. The Journal of Philosophy 73: 771-791. 1976. Reimpresso em: Moser, Paul K and Vander Nat, eds., Human Knowledge: Classical and Contemporary Approaches, Oxford University Press: 269-281. 1987.

What is Justified Belief? In: Justification and Knowledge,

George S. Pappas, ed. Dordrecht: Reidel. 1-23.1979.

_. Epistemology and Cognition. Cambridge: Harvard University

Press. 1986.

HUME, David. Tratado da Natureza Humana. $2^{\mathrm{a}}$ Ed. São Paulo: Editora UNESP, 2009.

LEWIS, David. Elusive Knowledge. Australasian Journal of Philosophy 74: p. 549-567. Reimpresso em: Keith DeRose and Ted A. Warfield eds., Skepticism: A Contemporary Reader. New York Oxford: Oxford University Press: p. 220-239. 1999.

MOORE, G. E. Certainty. In: Philosophical Papers. New York: Ed. Collier Books, 1962. [p. $223-246]$.

MOSER, P; MULDER, D \& TROUT, J. D. A Teoria do Conhecimento - Uma Introdução temática. São Paulo: Martins Fontes, 2004.

PORCHAT, O. Vida comum e ceticismo. São Paulo-SP, Editora Unesp, 2007.

RASMUSSEN, D. B. Austin and Wittgenstein on "doubt" and "knowledge". Reason Papers no I. Marquette University. 1974.

SCHAFFER, J. From contextualism to contrastivism. Philosophical Studies 119 (1-2): 73-103. 2004. 
Perspectiva Filosófica, vol. 45, n. 1, 2018

_. Contrastive knowledge. In Oxford studies in epistemology 1, edited by T. Gendler and J. Hawthorne, pp. 235-72. Oxford: Oxford University Press. 2005.

STROUD, Barry. El Escepticismo Filosófico y su Significación. México (DF): Ed. Fondo de Cultura Económica, 1990.

UNGER, Peter. Ignorance: a Case for Scepticism. Oxford: Oxford university press, 1975.

WILlIANS, Michael. Ceticismo. in Compêndio de Epistemologia. São Paulo-SP, Edições Loyola, 2012. 